Edited by Allan Beveridge, Femi Oyebode and Rosalind Ramsay

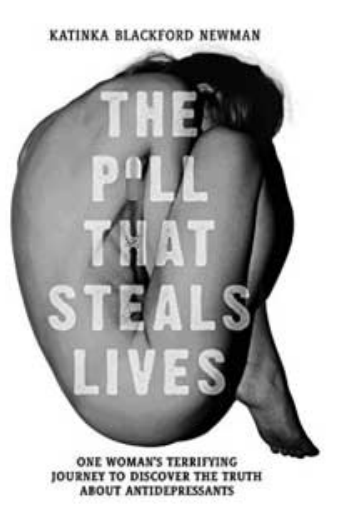

The Pill That Steals Lives

By Katinka Blackford Newman John Blake Publishing Ltd. 2016. f8.99 (pb). $288 \mathrm{pp}$. ISBN 9781786061331

The Pill That Steals Lives by Katinka Blackford Newman is an uncomfortable book for a psychiatrist to read. It is the story of a woman who experienced extreme distress and was diagnosed, rightly or wrongly, with psychotic depression. She was then prescribed an increasing array of psychotropic medications to little avail, and experienced horrible adverse effects, which resolved when she stopped them, along with her distress. This is eloquently told, and is a cautionary tale for all prescribers - somewhat reminiscent of swallowing the spider to catch the fly. She is horrified that she was prescribed such drugs, particularly SSRIs, for what she later perceives as a reaction to difficult life events, and, as a documentary filmmaker, resolves to tell her story and investigate further.

As both a prescriber and sometime recipient of psychotropic drugs, including SSRIs, I found myself pulled in opposite directions. It is impossible for any psychiatrist to comment retrospectively on either the author's diagnosis or the necessity at that time for medication. But, as a patient, I have far more mixed and personal feelings about psychotropic drugs and their significant adverse effects, and her descriptions resonated strongly. I was deeply struck by her frustrations when she tried to discuss her fears with doctors, and also with the bland dismissals that she had a 'chemical imbalance'. By simply telling her story, she raises questions and creates dissonance.

However, much of the book is concerned with the author's subsequent investigations, and, although interesting, this is less powerful and even detracts from her message. She raises important issues, particularly regarding Big Pharma and the hugely worrying expansion of prescribing indications. But ultimately the book never quite decides whether it is a personal testimony or a documentary, and the author's evidence and examples are paradoxically rendered less powerful by the context of her subjective experience and beliefs. I was also personally uncomfortable with her determination to involve her young children in her journey - although this may reflect my own preconceptions.

I strongly recommend reading this book, but to listen to the narrative rather than the explanations, and to draw one's own conclusions.

\footnotetext{
Rebecca Lawrence Consultant Psychiatrist, Ritson Clinic, Royal Edinburgh Hospital, Morningside Terrace, Edinburgh EH10 5HF, UK.

Email: rebecca.lawrence@nhslothian.scot.nhs.uk

doi: 10.1192/bjp.bp.116.191023
}

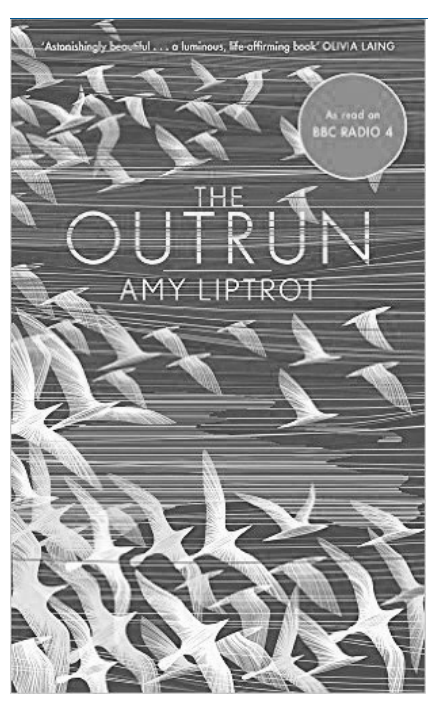

\section{The Outrun}

By Amy Liptrot

Canongate. 2016

f8.99 (pb). 304 pp.

ISBN 9781782115489
Described by her publishers as a writer, an artist's model, a trampolinist and a shellfish factory worker, Amy Liptrot's current profile comes from her autobiographical work, The Outrun, her first book. It has received critical praise and recently won the Wainwright Prize, an award sponsored by a brand of beer. This is not without irony, as The Outrun is a story of addiction and recovery, an account of dislocation from and rediscovery of origins, and an ode to the rugged Scottish Isles.

Liptrot's story is told in three parts. The book starts out frenetically with the chaos of youth, tenuous identity and addiction. Liptrot is born to Orkney newcomers, who struggle with the realities of building a life in an isolated community. They work to maintain the integrity of a family unit repeatedly buffeted by mental illness. Island life is inevitably different from the Orkney of tourist brochures and Liptrot shares with many of her contemporaries a powerful desire to leave. There is an aching sadness in the paradox of the young woman who moves away, seeking distance from her island origins yet never quite attaining a sense of belonging in her chosen refuge of London. There is desperation in her embrace of living fast, drinking heavily and careering out of control.

Liptrot returns home, fragile and bearing the fresh wounds of recovery. From here, the writing's manic fervour is replaced by a prose delivered with the slow pace and repetition of life's ebb and flow. We learn about bird watching, of island geography and the ways in which small communities synchronise with their environment. Finally, Liptrot draws an extended metaphor linking her evolving recovery with the unfinished geology of the land to which she has returned.

Written during the early part of her recovery, it is clear that the book served as powerful therapy for the author. The lengthy descriptions of landscape and the slow, rhythmic details of island life are the reflections of a tentative re-engagement with the world. As a counterpoint to the alcohol-fuelled chaos that enveloped her earlier life, the writing was ultimately too languid to hold my engagement. Perhaps this is the truest depiction of recovery: the acceptance of a slower and less dramatic life that stretches forward, long after the rapid, vibrant burn of addiction has passed.

Daniel V. Mogford ST5 Addiction Psychiatry, NHS Lothian, Substance Misuse Directorate, The Ritson Clinic, Royal Edinburgh Hospital, Edinburgh EH10 5HF, UK. Email: daniel.mogford@nhs.net

doi: 10.1192/bjp.bp.116.189480 